\title{
How Truth-Making Distributes
}

\author{
Robin Stenwall ${ }^{1}$ (i)
}

Received: 23 October 2020 / Accepted: 1 October 2021

(c) The Author(s) 2021

\begin{abstract}
In this paper I argue against the traditional view that truth-making distributes over entailment and present a novel account that takes truth-making to distribute over grounding between the existence of facts, thereby avoiding the shortcomings of the traditional view.
\end{abstract}

\section{Introduction}

Recall David Armstrong's Entailment Principle (2004: 10-12):

(EP) if $T$ makes $\langle\mathrm{P}\rangle$ true and $\langle\mathrm{P}\rangle$ entails $\langle\mathrm{Q}\rangle$, then $T$ makes $\langle\mathrm{Q}\rangle$ true, ${ }^{1}$

where the entailment in question is classical in that $\langle\mathrm{P}\rangle$ entails $\langle\mathrm{Q}\rangle$ if and only if it is impossible for $\langle\mathrm{P}\rangle$ to be true and $\langle\mathrm{Q}\rangle$ false.

(EP) is what I shall refer to as a 'distribution principle'. ${ }^{2}$ Such principles are valuable tools in truth-maker theory, as they can be used to reduce our ontological commitments. In view of (EP), there is no need to postulate a separate truth-maker for 〈the rose is coloured $\rangle$ over and above that for 〈the rose is red $\rangle$ as the former is entailed by the latter. Similar reasoning suggests that existential generalizations do not require their own separate truth-makers. If the fact that $a$ is $\mathrm{F}$ makes true $\langle a$ is $F\rangle$, then by (EP), the fact also makes true $\langle\exists x F(x)\rangle$. There is no need for a bespoke truth-maker in addition to the fact that $a$ is $\mathrm{F}$ whose sole purpose is to make true the existential generalization. The atomic fact suffices. ${ }^{3}$ (EP) has also been used to

\footnotetext{
Robin Stenwall

robin.stenwall@fil.lu.se

1 Department of Philosophy, Lund University, Lund, Sweden
}

1 I use angle brackets to denote propositions. Thus ' $\langle\mathrm{P}\rangle$ ' denotes the proposition that $\mathrm{P}$.

${ }^{2}$ I will follow Keller (2009) and Cameron (2008b) and talk about 'distribution' in this context. This locution is primarily used to describe what an operator does with respect to other operations as, for example, when conjunction distributes over disjunction, i.e. $(P \wedge(Q \vee R)) \Leftrightarrow(P \wedge Q) \vee(P \wedge R)$. However, if we are aware of the non-standard usage at play, this shouldn't pose a problem.

3 Similarly, there is no need to postulate a disjunctive entity that makes $\langle\mathrm{P} \vee \mathrm{Q}\rangle$ true: it suffices that there is a truth-maker for either disjunct. When it comes to conjunctions, matters are not as straightfor- 
reduce our ontological commitments for modal truths-albeit, less successfully so. Thus, Armstrong argues that (EP) can be used to provide truth-makers for 'mere possibilities' (i.e. contingent falsities). Suppose that $T$ makes some contingent $\langle\mathrm{P}\rangle$ true. Since the proposition is contingent, it entails that it is possible that not-P. From (EP) we obtain the result that $T$ also makes it true that it is possible that not-P (Armstrong, 2004, pp. 83-86). ${ }^{4}$ There is thus no need for a heavy ontological burdeneither in the form of an uncountable multitude of concrete possible worlds (Lewis, 1986) or in the form of an uncountable multitude of abstract possible worlds and haecceities (Plantinga, 1974) — to provide ontological grounding for mere possibilities. Any truth-maker for a contingent truth is automatically a truth-maker for the possibility of the complement of that contingent truth.

The above illustrates the importance of having an account of how truth-making distributes, especially if one takes the ontological commitments of a theory to be solely determined by that in virtue of which the theory is true (cf. Cameron, 2008a, 2008b). Unfortunately, although successful in some cases, (EP) will not do as a general distribution principle. The problem is that the notion of entailment is too coarsegrained to tell us how truth-making distributes. Every necessary truth is classically entailed by every truth, and every truth-maker makes some truth true. But if so, it follows that every truth-maker makes every necessary truth true. ${ }^{5}$ However, truthmaking is the relation we invoke to explain the truth of a proposition by reference to that which grounds its truth. But then whatever it is that grounds $\langle 4+8=12\rangle$ 's truth, it is clear that any arbitrary entity will not do. Even worse, (EP) has as a consequence that every truth-maker makes every truth true (whether necessary or contingent), given the independently plausible assumption that a truth-maker for a disjunction makes either disjunct true. ${ }^{6}$

None of the strategies devised to overcome these problems has been successful. There are those who accept (EP) but deny that a truth-maker for a disjunction must make either disjunct true (Read, 2000, p. 75). This avoids the second problem but not the first: every truth-maker would still make every necessary truth true. Another strategy is to block the route from the necessity of $\langle\mathrm{Q}\rangle$ to its entailment by an arbitrary $\langle\mathrm{P}\rangle$ by substituting relevant entailment for classical entailment. However, there are several systems of relevant logic, and there is no guarantee that any of these systems will have a notion of entailment that conforms to our conception of what makes

\footnotetext{
Footnote 3 (continued)

ward (Armstrong 1997, p. 35) and a distribution principle that avoids commitment to conjunctive entities in the same manner as it avoids commitment to disjunctive entities would have to allow for a nonconjunctive multitude of propositions to be made true jointly by several truth-makers. In the following, I will ignore this complication and assume that the present account can be amended to accommodate for conjunctive truths.

4 This way of reasoning is highly questionable (see Keller 2009, p. 1103) and Armstrong admitted that the argument was a 'sad blunder' (Armstrong 2007, p. 101). See also Pawl (2010).

${ }^{5}$ Let $T$ be any truth-maker and $\langle\mathrm{Q}\rangle$ any necessary truth. By assumption, $T$ makes some $\langle\mathrm{P}\rangle$ true. Since $\langle\mathrm{P}\rangle$ entails $\langle\mathrm{Q}\rangle$, it follows from (EP) that $T$ makes $\langle\mathrm{Q}\rangle$ true (Restall 1996, p. 333).

${ }^{6}$ Let $T$ be any truth-maker and $\langle\mathrm{Q}\rangle$ any truth. Suppose that $T$ makes some $\langle\mathrm{P}\rangle$ true. Since $\langle\mathrm{Q} \vee \sim \mathrm{Q}\rangle$ is a necessary truth and so entailed by $\langle\mathrm{P}\rangle$, it follows from (EP) that $T$ makes $\langle\mathrm{Q} \vee \sim \mathrm{Q}\rangle$ true. Given that a truth-maker for a disjunction is a truth-maker for either disjunct, $T$ makes $\langle\mathrm{Q}\rangle$ true or $T$ makes $\langle\sim \mathrm{Q}\rangle$ true. However, nothing makes $\langle\sim Q\rangle$ true, since $\langle\sim Q\rangle$ is false. And so, T makes $\langle Q\rangle$ true (Restall 1996, p. 333).
} 
what true (Rodriguez-Pereyra, 2006, p. 975). Yet another strategy is to hold on to the classical notion of entailment, but restrict the scope of (EP) to contingent truths. However, if we assume that a truth-maker for a conjunction is a truth-maker for each conjunct, this would still have the unwelcomed consequence that every truth-maker makes every necessary truth true. ${ }^{7}$

Intuitively, the problem with (EP) is that entailment (whether in the classical or in some relevant sense) does not preserve the groundedness of truth. It's thus natural to consider whether truth-making distributes across ground. Exactly how to understand this has not been much discussed. ${ }^{8}$ Perhaps this is because it has been assumed trivial. But it is not trivial, because it is not clear how the chaining procedure of determining what grounds what is meant to work if truth-making and grounding take different types of entities as their relata (Raven, 2013, p. 194; cf. Fine, 2012, pp. 44-45). To acquire such a procedure, it might be thought that we need to close the gap between truth-making and grounding. This can be done if we adopt what Kelly Trogdon (2020, p. 398) calls the simple grounding-theoretic account of truth-making according to which $T$ makes $\langle\mathrm{P}\rangle$ true if and only if $T$ grounds the fact that $\langle\mathrm{P}\rangle$ is true. Let ' $[\mathrm{P}]$ ' denote the fact that $\langle\mathrm{P}\rangle$. The simple grounding-theoretic account of truth-making then says that:

$\left(\mathrm{TM}_{\mathrm{F}}\right) \quad T$ makes $\langle\mathrm{P}\rangle$ true if and only if $T$ grounds $\left[\langle\mathrm{P}\rangle\right.$ is true]. ${ }^{9}$

In the following I assume that truth-makers can belong to multiple ontological categories and that the categories involved in specific truth-making instances need not be the same (Cameron, 2008a \& Schaffer, 2009). I will also assume that a proposition need not be made true by a single entity, but can be made true jointly by several entities. I thus allow ' $T$ ' to state a list of more than one single term (cf. Correia, 2011).

Now, assuming that truth-making as depicted by $\left(\mathrm{TM}_{\mathrm{F}}\right)$ is not obviously non-transitive (Griffith, 2014 \& Rodriguez-Pereyra, 2015), one could argue for the following principle:

$\left(\mathrm{DP}_{\mathrm{F}}\right) \quad$ if $T$ grounds $[\langle\mathrm{P}\rangle$ is true] and $[\langle\mathrm{P}\rangle$ is true] grounds $[\langle\mathrm{Q}\rangle$ is true], then $T$ grounds $[\langle\mathrm{Q}\rangle$ is true].

$\left(\mathrm{DP}_{\mathrm{F}}\right)$ doesn't have the same problems as (EP) with necessary truths. Grounds contribute to explaining what they ground, and a fact about the truth of some arbitrary

\footnotetext{
${ }^{7}$ Let $T$ be any truth-maker and $\langle\mathrm{Q}\rangle$ any necessary truth. Suppose that $T$ makes true some contingent $\langle\mathrm{P}\rangle$. Since $\langle\mathrm{P}\rangle$ entails $\langle\mathrm{P} \wedge \mathrm{Q}\rangle$ and the conjunction is contingent, it follows from (EP) in its restricted form that $T$ makes $\langle\mathrm{P} \wedge \mathrm{Q}\rangle$ true. But if a truth-maker for a conjunction is a truth-maker for each conjunct, then $T$ makes $\langle Q\rangle$ true (Restall 1996, p. 334). Armstrong (2004, pp. 11-12) thinks that this conclusion can be avoided if we restrict (EP) to, what he calls, 'purely contingent' truths: i.e. truths that do not contain any necessary truth at any level of analysis. For a discussion of why this strategy fails, see Rodriguez-Pereyra (2006).

${ }^{8}$ An exception is Correia (2011).

9 Tahko (2013) and Griffith (2014, p. 204) discuss similar proposals.
} 
$\langle\mathrm{P}\rangle$ need not explain why some necessary truth is true. Thus $\left(\mathrm{DP}_{\mathrm{F}}\right)$ is not open to the objection that it makes every truth-maker into a truth-maker for every necessary truth. Similarly, assuming that a truth-maker for a disjunction is a truth-maker for either disjunct, it does not follow that every truth-maker makes every truth true.

$\left(\mathrm{TM}_{\mathrm{F}}\right)$ and $\left(\mathrm{DP}_{\mathrm{F}}\right)$ readily square with the orthodox view that grounding can only relate facts (Audi, 2012 \& Rosen, 2010). Although I will not argue the point here in detail, I think that the orthodoxy is false and that the relata of grounding can be members of any ontological category. In fact, anyone who thinks that truth-making can be analysed in terms of grounding should accept this as it would seem that $\langle$ there are properties and 〈there are particulars〉 are respectively made true by any property and particular rather than by facts about the existence of some property or particular (cf. Griffith, 2014, p. 203). What is more, I also think that the notion at play in $\left(\mathrm{TM}_{\mathrm{F}}\right)$ is not what is meant by 'making true'. Truth-making is thought to be a cross-categorical relation that holds between an entity (or entities) in the world and true propositions (Armstrong, 2004, pp. 5-6). $\left(\mathrm{TM}_{\mathrm{F}}\right.$ ), however, takes truth-making to hold between an alethic fact (i.e. a fact about the truth value of a proposition) and whatever it is that grounds that fact. But truth-maker theory is not concerned with what grounds alethic facts, it is concerned with what grounds truth.

More alarming, however, is that even if we grant that truth-making is a matter of alethic-fact grounding, there is reason to think that truth-making as depicted by $\left(\mathrm{TM}_{\mathrm{F}}\right)$ isn't transitive and that there are instances where $\left(\mathrm{DP}_{\mathrm{F}}\right)$ comes out false. To illustrate, assuming that truths of the form $\langle a$ exists $\rangle$ are made true by $a$, the following claims both seem true:

(1) Socrates grounds [ $[$ Socrates exists $\rangle$ is true]

(2) $[\langle$ Socrates exists $\rangle$ is true $]$ grounds [ $\langle$ there are alethic facts $\rangle$ is true $]$.

Transitivity gives us:

(3) Socrates grounds [ $\langle$ there are alethic facts $\rangle$ is true $]$.

But (3) can't be true. No doubt, assuming that truths of the form $\langle a$ exists $\rangle$ are made true by $a$ and that truth-making works as depicted by $\left(\mathrm{TM}_{\mathrm{F}}\right)$, one is committed accepting that Socrates grounds [ $\langle$ Socrates exists $\rangle$ is true]. What is more, being an existential generalization, one would expect $\langle$ there are alethic facts $\rangle$ to be made true by an alethic fact and so, that [ $\langle$ Socrates exists $\rangle$ is true] suffices to ground the fact that there are alethic facts in accordance with $\left(\mathrm{TM}_{\mathrm{F}}\right) .{ }^{10}$ Socrates, however, is not an alethic fact, nor is he alone sufficient to ground the fact that the proposition that there are alethic facts is true. ${ }^{11}$ To provide a sufficient ground for that fact we need, in addition to Socrates, also the proposition that Socrates exists- the ground(s) for

\footnotetext{
$\overline{10}$ [〈Socrates exists $\rangle$ is true], I take it, is essentially an alethic fact.

${ }^{11}$ The same argument applies if we identify the ground for [〈Socrates exists $\rangle$ is true] with [Socrates exists].
} 
which is not provided by Socrates alone. Hence, (3) is false. We will have reason to return to a more detailed discussion about the failure of transitivity in Sect. 3.

In view of the above, let us say that:

$\left(\mathrm{TM}_{\mathrm{T}}\right) \quad T$ makes $\langle\mathrm{P}\rangle$ true if and only if $T$ grounds $\langle\mathrm{P}\rangle$ 's truth,

thereby making it explicit that truth-making is a matter of grounding the truth of propositions. ${ }^{12}$ This, I take it, is more in line with truth-maker theory than is $\left(\mathrm{TM}_{\mathrm{F}}\right) \cdot{ }^{13}$ By making use of $\left(\mathrm{TM}_{\mathrm{T}}\right)$, one might suggest that truth-making distributes as follows:

$\left(\mathrm{DP}_{\mathrm{T}}\right) \quad$ if $T$ grounds $\langle\mathrm{P}\rangle$ 's truth and $\langle\mathrm{P}\rangle$ 's truth grounds $\langle\mathrm{Q}\rangle$ 's truth, then $T$ grounds $\langle\mathrm{Q}\rangle$ 's truth.

Like $\left(\mathrm{TM}_{\mathrm{F}}\right)$ the above principle avoids the problems generated by necessary truths, but it does so without equating truth-making with alethic-fact grounding.

Although an improvement over $\left(\mathrm{DP}_{\mathrm{F}}\right),\left(\mathrm{DP}_{\mathrm{T}}\right)$ faces at least two difficulties. First of all, it is not clear whether $\left(\mathrm{DP}_{\mathrm{T}}\right)$ is general enough to cover all instances where truth-making is thought to distribute. Thus, we would expect [the rose is red] to ground the truth of both $\langle$ the rose is red $\rangle$ and $\langle$ the rose is coloured $\rangle$; but it is hard to see in what sense the truth of the former proposition can be said to ground the truth of the latter. Intuitively, what makes the truth-predicate apply to 〈the rose is coloured $\rangle$ is not the truth of some proposition, but a worldly fact, say, [the rose is red]. Of course, the truth of $\langle$ the rose is coloured $\rangle$ is guaranteed by the truth of $\langle$ the rose is red $\rangle$ in that there is no possible world in which the latter is true and the former false; but this is just the entailment of one proposition by another, not the kind of grounding connection that concerns us here. This is not to say that there are no instances where $\left(\mathrm{DP}_{\mathrm{T}}\right)$ comes out true. After all, there are cases where the truth of a proposition serves to ground (and thus, metaphysically explain) the truth of some other proposition that it entails as, for example, when the truth of 〈Socrates exists〉 grounds the truth of both $\langle\langle$ Socrates exists $\rangle$ is true $\rangle$ and $\langle$ there are truths $\rangle$ (see below). In each of these cases, however, something in addition to mere entailment is needed to account for why the truth-predicate applies to 〈〈Socrates exists〉 is true $\rangle$ and $\langle$ there are truths $\rangle$ by virtue of $\langle$ Socrates exists $\rangle$ 's truth—whether the addition is

\footnotetext{
12 All this means is that the truth-predicate applies to a proposition by virtue of its truth-maker. It does not matter for present purposes what kind of entities you think nominalized expressions like 'the F-ness of $x$ ' or ' $x$ 's F-ness' refer to, as long as they are taken to be property exemplifications of objects rather than facts of the form $[\mathrm{x}$ is $\mathrm{F}]$.

${ }^{13}$ Still, I take it that there are those who are not convinced. To accommodate those who take truth-making to be a matter of alethic-fact grounding, I've included footnotes throughout the text where I discuss how $\left(\mathrm{TM}_{\mathrm{F}}\right)$ can be utilized to provide an adequate distribution principle.
} 
in the essence of truth, ${ }^{14}$ in the laws of metaphysics (Glazier, 2016; Kment, 2014; Schaffer, 2017; Wilsch, 2015) or in underlying determination relations (Trogdon, 2018, 2020, pp. 396-407). Whatever the case may be, in instances where one proposition merely entails another it is not clear whether there are any such additions (or if they are needed) and therefore, I claim, there is no reason to think that $\left(\mathrm{DP}_{\mathrm{T}}\right)$ covers all cases where truth-making is said to distribute.

Secondly, even if we can make sense of grounding orderings among truths that merely entail one another (perhaps the fundamental story about propositions requires such orderings), $\left(\mathrm{DP}_{\mathrm{T}}\right)$ is subject to a similar criticism that was levelled against the alleged transitivity of $\left(\mathrm{DP}_{\mathrm{F}}\right)$. Again, suppose that truths of the form $\langle a$ exists $\rangle$ are made true by $a$. The following claims are both true:

(4) Socrates grounds $\langle$ Socrates exists $\rangle$ 's truth

(5) 〈Socrates exists $\rangle$ 's truth grounds $\langle$ there are truths $\rangle$ 's truth.

$\left(\mathrm{DP}_{\mathrm{T}}\right)$ predicts that:

(6) Socrates grounds $\langle$ there are truths $\rangle$ 's truth.

But again, (6) can't be true. Assuming that truths of the form $\langle a$ exists $\rangle$ are made true by $a$ and that truth-making works in accordance with $\left(\mathrm{TM}_{\mathrm{T}}\right)$, we are committed accepting that the philosopher taken by himself provides a sufficient ground for 〈Socrates exists〉's truth. Moreover, assuming that the truth of an existential generalization like $\langle$ there are truths $\rangle$ is made true by any truth, then, in view of $\left(\mathrm{TM}_{\mathrm{T}}\right)$, it follows that the truth of 〈there are truths $\rangle$ is grounded in 〈Socrates exists〉's truth. But, of course, Socrates himself is not a truth, nor is Socrates alone sufficient to make 〈there are truths $\rangle$ true in the manner depicted by $\left(\mathrm{TM}_{\mathrm{T}}\right) .{ }^{15} \mathrm{We}$ will discuss why this is so in Sect. 3.

I conclude that the prospect of using either $\left(\mathrm{DP}_{\mathrm{F}}\right)$ or $\left(\mathrm{DP}_{\mathrm{T}}\right)$ as a distribution principle looks bleak.

\section{Truth-Making Distributes Across the Existence of Facts}

My proposal for how truth-making distributes trades on the uncontentious assumption that in addition to the truth of propositions being grounded, the existence (or obtaining) of facts is also grounded. Facts are here taken to be the worldly correspondents of true propositions given by the principle that $\langle\mathrm{P}\rangle$ is true if and only

\footnotetext{
${ }^{14}$ Thus, for example, one could plausibly claim that it is essential to the truth of any $\langle\mathrm{P}\rangle$, that if $\langle\mathrm{P}\rangle$ is true so is the proposition stating that $\langle\mathrm{P}\rangle$ is true and $\langle$ there are truths $\rangle$.

${ }^{15}$ The same argument applies if we identify the ground for 〈Socrates exists〉's truth with [Socrates exists].
} 
if $[\mathrm{P}]$ exists. ${ }^{16}$ In other words, facts are what propositions state when they are true (Mellor, 1995, pp. 8-9). I will continue to use nominalized expressions to indicate which feature (or mode) of that which grounds or gets grounded I have in mind. Thus understood, both truth-making and existence-making are factive in that:

$T$ grounds $\langle\mathrm{P}\rangle$ 's truth.

holds only if $\langle\mathrm{P}\rangle$ is true and:

$T$ ss existence grounds [P]'s existence.

holds only if [P] exists.

The idea I want to defend is that truth-making distributes as follows:

$\left(\mathrm{DP}_{\mathrm{E}}\right) \quad$ if $T$ grounds $\langle\mathrm{P}\rangle$ 's truth and [P]'s existence grounds [Q]'s existence, then $T$ grounds $\langle\mathrm{Q}\rangle$ 's truth.

The principle holds true for all instances of $T$ and $\langle\mathrm{P}\rangle$ because on our trivial definition of 'fact', for any true $\langle\mathrm{P}\rangle,\langle\mathrm{P}\rangle$ 's truth is metaphysically aligned with [P]'s existence. For any entities $X$ and $Y$, we say that $X$ and $Y$ are metaphysically aligned if and only if $X$ and $Y$ share the same possible grounds, i.e. every possible ground for $X$ is also a possible ground for $Y$ and vice versa. ${ }^{17}$ Thus, for example, the existence of [the rose is coloured] is metaphysically aligned with 〈the rose is coloured)'s truth in that any possible ground for the existence of [the rose is coloured] - whether it be [the rose is red], [the rose is yellow], [the rose is blue], or what have you-also serves to ground the truth of $\langle$ the rose is coloured $\rangle$ and conversely.

Put differently, metaphysically aligned entities make the same exact demand on the underlying ontology. Thus, let $T$ be any truth-maker and $\langle\mathrm{P}\rangle$ any truth, such that $T$ grounds $\langle\mathrm{P}\rangle$ 's truth. Since truth-making is factive and $\langle\mathrm{P}\rangle$ is true if and only if $[\mathrm{P}]$ exists, it follows that $\langle\mathrm{P}\rangle$ is true and that $[\mathrm{P}]$ exists. But by assumption, the truth of $\langle\mathrm{P}\rangle$ is metaphysically aligned with [P]'s existence and so, we get that $T$ also grounds

\footnotetext{
${ }^{16}$ According to the worldly conception, facts have worldly constituents (i.e. particulars and properties) as opposed to representations or modes thereof. I will assume that the properties involved in facts can be both of the abundant and sparse variety (Lewis 1986). Thus, although I assume that there is a one-one correspondence between truths and facts in the trivial sense of 'fact' above, I reject the idea that for each true $\langle\mathrm{P}\rangle$, there corresponds a fact $[\mathrm{P}]$ in the ontologically serious sense of 'fact' according to which they are particulars instantiating sparse properties, i.e. universals. The world of facts that should be taken with ontological seriousness is a sparsely populated realm, whereas there exists (by definition) as many trivial facts as there are truths (cf. Mellor 1995, p. 159). This makes the trivial notion of 'fact' useless for a correspondence theory of truth as the notion would make the theory either vacuous or false. But, of course, I'm not using facts to define truth: like Mellor (1995, p. 9), I'm using truths to define facts.

${ }^{17}$ Fabrice Correia (2010, pp. 256-259) makes use of a similar notion that he calls 'metaphysical equivalence', where for any $p$ and $q, p$ is metaphysically equivalent to $q$ if and only if $p$ and $q$ share the same possible grounds and groundees (i.e. what is grounded). In addition of metaphysical alignment being a weaker notion than metaphysical equivalence, the two differ in that the former is a relation that can obtain between entities from various ontological categories, whereas the latter is a sentential operator.
} 
$[\mathrm{P}]$ 's existence. Assuming that [P]'s existence grounds $[\mathrm{Q}]$ 's existence and that existence-making is transitive, it follows that $T$ grounds [Q]'s existence. ${ }^{18}$ Finally, since the truth of $\langle Q\rangle$ is metaphysically aligned with [Q]'s existence, we obtain the result that $T$ grounds $\langle\mathrm{Q}\rangle$ 's truth. ${ }^{19}$

It is important to see why we should opt for $\left(\mathrm{DP}_{\mathrm{E}}\right)$ rather than:

\section{(DP) if $T$ grounds $\langle\mathrm{P}\rangle$ 's truth and [P] grounds [Q], then $T$ grounds $\langle\mathrm{Q}\rangle$ 's truth,}

where truth-making distributes across the grounding of facts simpliciter. In order for (DP) to work, the principle requires for any truth $\langle\mathrm{P}\rangle$, that $\langle\mathrm{P}\rangle$ 's truth is metaphysically aligned with $[\mathrm{P}]$. But this can't be true. To see why, suppose that $[\mathrm{P}]$ is fundamental. On the grounding-based characterization, fundamentalia lack grounds and everything is either ungrounded or ultimately grounded in the fundamental (Schaffer, 2009, p. 353; Audi, 2012, p. 710; Dasgupta, 2014, p. 536; Raven, 2016, p. 613). But although $[\mathrm{P}]$ might be fundamental, the truth of $\langle\mathrm{P}\rangle$ can't be, as truth is not a fundamental feature of propositions (Schaffer, 2008, p. 308). As such, $\langle\mathrm{P}\rangle$ 's truth requires something that grounds it and the most plausible view is that $\langle\mathrm{P}\rangle$ 's truth is grounded in $[\mathrm{P}]$. Consequently, $\langle\mathrm{P}\rangle$ 's truth and $[\mathrm{P}]$ are not metaphysically aligned as the former is grounded and the latter is not. Thus, (DP) can't be true. ${ }^{20}$

On the present view, the situation concerning grounds for the existence of facts is analogous to the situation concerning grounds for the truth of propositions. Just as truth is not a fundamental feature of propositions, existence is not a fundamental feature of facts. ${ }^{21}$ It is thus not the case for any truth $\langle\mathrm{P}\rangle$ that $[\mathrm{P}]$ 's existence

\footnotetext{
${ }^{18}$ An alternative to $\left(\mathrm{DP}_{\mathrm{E}}\right)$ is to say that if $T$ grounds $\langle\mathrm{P}\rangle$ 's truth and $[\mathrm{P}]$ 's existence grounds $\langle\mathrm{Q}\rangle$ 's truth, then $T$ also grounds $\langle\mathrm{Q}\rangle$ 's truth. However, this would require a transitive chain where some of the links are instances of truth-making and others are instances of existence-making. An account that solely relies on the transitivity of existence-making is to be preferred over a hybrid one.

19 There is an analogous argument to be found for those who take truth-making to be a matter of alethicfact grounding. By making use of the following principle:

$$
\left(\mathrm{DP}_{\mathrm{E}}^{*}\right) \quad \text { if } T \text { grounds }[\langle\mathrm{P}\rangle \text { is true] and [[P] exists] grounds [[Q] exists], then } T
$$
grounds $[\langle\mathrm{Q}\rangle$ is true],
}

and the claim that for any true proposition $\langle\mathrm{P}\rangle$, $[\langle\mathrm{P}\rangle$ is true] is metaphysically aligned with $[[\mathrm{P}]$ exists], they could argue as follows: let $T$ be any truth-maker and $\langle\mathrm{P}\rangle$ any true proposition, such that $T$ grounds $[\langle\mathrm{P}\rangle$ is true]. Since truth-making is factive and $\langle\mathrm{P}\rangle$ is true if and only if [P] exists, it is a fact that $\langle\mathrm{P}\rangle$ is true and a fact that $[\mathrm{P}]$ exists. But $[\langle\mathrm{P}\rangle$ is true] is metaphysically aligned with $[[\mathrm{P}]$ exists] and so, $T$ also grounds $[[\mathrm{P}]$ exists]. Assuming that $[[\mathrm{P}]$ exists] grounds $[[\mathrm{Q}]$ exists] and that the grounding of worldly facts is transitive, it follows that $T$ grounds [[Q] exists]. From the metaphysical alignment of [ $\langle\mathrm{Q}\rangle$ is true] and $[[\mathrm{Q}]$ exists], we get that $[\langle\mathrm{Q}\rangle$ is true] is grounded by $T$.

${ }^{20}$ Assuming that fundamental facts are self-grounded, it would be possible to uphold the thesis that $\langle\mathrm{P}\rangle$ 's truth is metaphysically aligned with $[\mathrm{P}]$ as both $\langle\mathrm{P}\rangle$ 's truth and $[\mathrm{P}]$ would then be grounded in [P]. I take this to be a too high price to pay for a marginally simpler principle like (DP).

${ }^{21}$ The reason that truth isn't a fundamental feature of propositions is not that they can exist and yet not be true, but that for any true $\langle\mathrm{P}\rangle,\langle\mathrm{P}\rangle$ 's truth is a relational feature that $\langle\mathrm{P}\rangle$ has by virtue of standing in the truth-making relation to whatever it is that makes the truth-predicate apply to $\langle\mathrm{P}\rangle$. The same, I argue, holds true of the existence of facts. Thus, for any existing [P], [P]'s existence is a relational feature of $[\mathrm{P}]$ that it has by virtue of standing in the existence-making relation to whatever it is that makes the existence-predicate apply to [P]. Although I will not argue the point here, my own view is that there is no distinction to be drawn between being and existence and that nothing can relate anything to nothing. I thus reject the view that just as there can be false propositions that are made true by their truth-makers, 
is fundamental. When $\langle\mathrm{P}\rangle$ corresponds to a fundamental fact $[\mathrm{P}]$, the ontological grounding for $\langle\mathrm{P}\rangle$ 's truth and [P]'s existence is provided by $[\mathrm{P}]$ itself. $^{22}$ Consequently, although the presence of fundamental facts falsifies (DP), it does not falsify $\left(\mathrm{DP}_{\mathrm{E}}\right)$ nor the claim that every possible ground for $\langle\mathrm{P}\rangle$ 's truth is also a possible ground for the existence of $[\mathrm{P}]$, and vice versa. ${ }^{23}$

It is easy to see how $\left(\mathrm{DP}_{\mathrm{E}}\right)$ does better than both $(\mathrm{EP})$ and $\left(\mathrm{DP}_{\mathrm{F}}\right)$. In order for truth-making to distribute, $\left(\mathrm{DP}_{\mathrm{E}}\right)$ requires, not that $\langle\mathrm{P}\rangle$ entails $\langle\mathrm{Q}\rangle$, but that $[\mathrm{P}]$ 's existence grounds [Q]'s existence. As such, the principle is not subject to the same problems concerning necessary truths that was levelled against (EP). What is more, it avoids these problems without equating truth-making with alethic-fact grounding-this, since $\left(\mathrm{DP}_{\mathrm{E}}\right)$ takes the truth-making relation to hold between a truthmaker and a truth, rather than, as in $\left(\mathrm{DP}_{\mathrm{F}}\right)$, where truth-making holds between a truth-maker and a fact about a proposition being true. And since $\left(\mathrm{DP}_{\mathrm{E}}\right)$ does not take truth-making to be a matter of alethic-fact grounding, it does not require that the notion of grounding at play is transitive (more on transitivity below).

To see how $\left(\mathrm{DP}_{\mathrm{E}}\right)$ compares to $\left(\mathrm{DP}_{\mathrm{T}}\right)$ is a bit more complicated. In the previous section we saw that it is difficult to make sense of the idea that the truth of a proposition grounds the truth of another proposition. To the extent that it makes sense to speak of a grounding ordering among truths, it is indirectly by reference to the grounding ordering among the facts that the truths correspond to. $\left(\mathrm{DP}_{\mathrm{E}}\right)$ takes this at face value by recognizing truth-making to distribute, not across the grounding of truths, but across the grounding between the existence of worldly facts. We also saw that even if we somehow make sense of grounding orderings among truths, the notion of truth-making at play in $\left(\mathrm{DP}_{\mathrm{T}}\right)$ isn't transitive, and so there would be instances of truths and truth-makers, where the principle comes out false. Now, $\left(\mathrm{DP}_{\mathrm{T}}\right)$ and $\left(\mathrm{DP}_{\mathrm{E}}\right)$ do not differ with respect to the notion of truth-making at play. Still, the latter principle is valid (or so I claim), whereas the former principle isn't. Part of the reason that $\left(\mathrm{DP}_{\mathrm{T}}\right)$ fails as a distribution principle is that the truth

Footnote 21 (continued)

there can be non-existent facts that are made existent by their existence-makers. For further details, see fn. 24 and Sect. 3.

22 Similarly, for any true $\langle\mathrm{P}\rangle$, neither $[\langle\mathrm{P}\rangle$ is true] nor $[[\mathrm{P}]$ exists] is fundamental. When $\langle\mathrm{P}\rangle$ corresponds to a fundamental fact, it is $[\mathrm{P}]$ itself that provides the ground for both $[\langle\mathrm{P}\rangle$ is true $]$ and $[[\mathrm{P}]$ exists].

23 At first glance, this seems to go against the truth-maker idea that truth is grounded in existence (cf. Cameron 2008a, p. 112). Thus, Kit Fine writes that, grounds for truths "should take the form of existential attributions; it is always the existence of something that properly accounts for the truth of the representations" (2012, pp. 43-44). But by taking $\langle\mathrm{P}\rangle$ 's truth and [P]'s existence to be metaphysically aligned for all truths $\langle\mathrm{P}\rangle$, one is forced to deny that $[\mathrm{P}]$ 's existence grounds $\langle\mathrm{P}\rangle$ 's truth, as this would imply that $[\mathrm{P}]$ 's existence grounds itself. So, on pain of violating the irreflexivity of existence-making, it seems that we have to go against the truth-maker intuition and identify the grounds for truth with something other than its grounds' existence.

In response, truth-maker theorists are not committed to identifying grounds for truths with the existence of anything (cf. Asay 2017, p. 448). It is a misrepresentation of truth-maker theory that, as far as I can tell, has its roots in the divine decree argument that "for God to give a complete plan of the world He needs only make an inventory of what is to exist" (Cameron 2008a, pp. 112-113). This might be true. But for God to make an inventory of what is to exist, there is no need for him to create the existence of everything there is. It suffices that He makes all there is. 
of a proposition can itself serve as truth-maker, e.g. when (Socrates exists〉's truth grounds the truth of $\langle$ there are truths $\rangle$. This possibility is blocked by $\left(\mathrm{DP}_{\mathrm{E}}\right)$ since the chain that links the grounding of $\langle\mathrm{P}\rangle$ 's truth in $T$ with the grounding of $\langle\mathrm{Q}\rangle$ 's truth in $T$ does not hold between the truth of propositions but between the existence of facts. Thus, there is a shift in the second term from:

$T$ grounds $\langle\mathrm{P}\rangle$ 's truth.

to the first term in.

$[\mathrm{P}]$ 's existence ground [Q]'s existence.

In effect, the chaining is cut as $\left(\mathrm{DP}_{\mathrm{E}}\right)$ does not require that $\langle\mathrm{P}\rangle$ 's truth grounds $\langle\mathrm{Q}\rangle$ 's truth but that the existence of the fact stated by $\langle\mathrm{P}\rangle$ grounds the existence of the fact stated by $\langle\mathrm{Q}\rangle$. And although the truth of $\langle$ Socrates exists $\rangle$ grounds the truth of $\langle$ there are truths $\rangle$, it isn't the case that [Socrates exists]'s existence grounds [there are truths]'s existence. Consequently, $\left(\mathrm{DP}_{\mathrm{E}}\right)$ does not require that truth-making as depicted by $\left(\mathrm{TM}_{\mathrm{T}}\right)$ is transitive. Nor, for the same reason, does it require that grounding is transitive (which, of course, it can't be given that truth-making is a matter of grounding truth in accordance with $\left.\left(\mathrm{TM}_{\mathrm{T}}\right)\right) .{ }^{24}$ It does, however, rest on the assumption that existence-making is transitive. This might seem surprising in light of the alleged non-transitivity of truth-making, which is why it is useful for clarificatory purposes to dedicate the last section to a discussion about the way in which truth-making and existence-making differ.

\section{Transitivity and the Ontological Free Lunch}

Consider the existence-making analogue of (4)-(6). Given that 〈Socrates exists〉's truth and [Socrates exists]'s existence are metaphysically aligned and (4) is true, it follows that:

\section{(7) Socrates grounds [Socrates exists]'s existence}

But it is also true that:

(8) [Socrates exists]'s existence grounds [there are facts]'s existence.

Which, if existence-making is transitive, gives us:

(9) Socrates grounds [there are facts]'s existence.

\footnotetext{
${ }^{24}$ Similarly, part of the reason that $\left(\mathrm{DP}_{\mathrm{F}}\right)$ fails is that alethic facts can serve as grounds for other alethic facts, as when [Socrates exists is true] grounds [there are alethic facts is true]. This possibility is blocked by $\left(\mathrm{DP} *_{\mathrm{E}}\right.$ ) (see fn. 20) as it takes truth-making to distribute over worldly facts and it is generally not the case that although $[\langle P\rangle$ is true] grounds $[\langle\mathrm{Q}\rangle$ is true], that $[[\mathrm{P}]$ exists] grounds $[[\mathrm{Q}]$ exists].
} 
But why think that (9) is true? Socrates, of course, is not a truth. But if Socrates does not suffice on his own to ground the truth of 〈there are truths〉, why think that the philosopher alone suffices to ground the existence of [there are facts]? After all, Socrates isn't a fact either.

The alleged transitivity of existence-making has been subject to counterexamples (Schaffer, 2012 \& Tahko, 2013). But it remains controversial whether the counterexamples succeed (Litland, 2013; Raven, 2013; Rodriguez-Pereyra, 2015) and many grounding theorists accept (plausibly for theoretical reasons) the transitivity of existence-making, as this (together with irreflexivity) generates a partial ordering that induces metaphysical structure. I take the advantages of a hierarchical structure that takes us from the less fundamental to the increasingly fundamental to outweigh any problems raised by contentious counterexamples to transitivity. Such a structure is important as it accounts for the existential dependence that holds between various entities in the hierarchy.

There is, however, an important difference between existence-making and truthmaking that provides some theory independent justification for the conclusion that (7)-(9) form a transitive chain, whereas (4)-(6) do not. For even assuming that they are both instances of grounding, the relation that holds between an existent fact and its ground(s) is innocuous in that the existence of the grounded fact does not add to the ontology of its ground(s), whereas the relation that holds between a truth and its ground(s) does. The existence of a grounded fact is, to use Armstrong's expression, an "ontological free lunch" (1997, pp. 12-13) that does not add anything extra 'over and above' its ground(s). There is, in this sense, nothing more to [Socrates exists]'s existence than Socrates himself. But if this is true and the existence of [there are facts] is grounded in the existence of [Socrates exists], we have to conclude that the existence of [there are facts] is also grounded in Socrates-this, since [Socrates exists]'s existence is nothing in addition to the philosopher. Consequently, (7)-(9) form a transitive chain.

Truth-making, by contrast, adds to the ontology of the situation. ${ }^{25}$ For although a truth-maker grounds the truth of the proposition it makes true, it does not ground the existence of the proposition to which the truth applies. Whatever the ground(s) for the existence of an inherently representational entity like $\langle\mathrm{P}\rangle$ may be, it must be something 'over and above' $\langle\mathrm{P}\rangle$ 's truth-maker. ${ }^{26}\langle\mathrm{P}\rangle$ 's truth will thus add to the

\footnotetext{
${ }^{25}$ One could argue that truth-making, like existence-making, is ontologically innocuous by adopting an identity theory of truth, according to which for any true proposition $\langle\mathrm{P}\rangle,\langle\mathrm{P}\rangle$ 's truth $=[\mathrm{P}]$. One could then use identity elimination to argue from the fact that [Socrates exists] is nothing 'over and above' Socrates to the conclusion that Socrates exists's truth is nothing 'over and above' Socrates. If so, both (4)-(6) and (7)-(9) would express transitive chains. But this solution is incompatible with the present account according to which $\langle\mathrm{P}\rangle$ 's truth must be thought of as distinct from that which makes it true. Thus, truthmakers can be fundamental, whereas $\langle\mathrm{P}\rangle$ 's truth can't be even when $\langle\mathrm{P}\rangle$ states a fundamental fact (see Sect. 2. above). Moreover, the identity theory of truth is independently implausible (Candlish 2015) and there are strong reasons to suggest that it is incompatible with some of the central tenets of truth-maker theory (Rodriguez-Pereyra 2005, pp. 29-31).

${ }^{26}$ Notice that if propositions are necessary existents, then $\langle\mathrm{P}\rangle$ 's existence is guaranteed independently of whatever it is that grounds $\langle\mathrm{P}\rangle$ 's truth (assuming that $\langle\mathrm{P}\rangle$ 's truth-maker is a contingent existent). Even so, the existence of $\langle\mathrm{P}\rangle$ will be ontologically additional to whatever it is that grounds $\langle\mathrm{P}\rangle$ 's truth.
} 
ontology of whatever it is that grounds it. ${ }^{27}$ For while it takes a single individual like Socrates to make a fact, it takes two-a truth-maker and a proposition-to make a truth. And a truth (i.e. a true proposition) is exactly what (there are truths〉 requires in order to be true. Consequently, although Socrates is perfectly sufficient on his

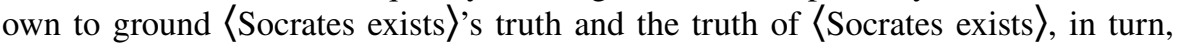
suffices to ground 〈there are truths〉's truth, the philosopher taken by himself is not sufficient to ground the truth of 〈there are truths〉.To provide a sufficient ground for 〈there are truths 〉's truth we need, in addition to Socrates, the proposition that Socrates exists. ${ }^{28}$ And whatever it is that grounds 〈Socrates exists)'s existence, it must be something ontologically additional to Socrates. ${ }^{29}$ I thus think that there are theory-independent reasons to suggest that existence-making is transitive whereas truth-making is not, and that the innocuous nature of the former and the not-soinnocuous nature of the latter, explains this difference.

\section{Summary}

I have argued that truth-making distributes across grounding between the existence of facts in the trivial sense according to which $\langle\mathrm{P}\rangle$ is true if and only if $[\mathrm{P}]$ exists. The corresponding principle allows us to preserve the groundedness of truth in a way that avoids the shortcomings of taking truth-making to distribute across grounding between alethic facts, truths or facts simpliciter. $\left(\mathrm{DP}_{\mathrm{E}}\right)$ is, in this sense, a step in the right direction as it diminishes the need for bespoke truth-makers as we ascend up 'the great chain of being'.

Acknowledgements I would like to thank the anonymous reviewers for their insightful comments. I am also indebted to the participants at the Metaphysical Explanation III workshop at Lund University, the Research Seminar at the University of Gothenburg and the Higher Seminar at Lund University. I would particularly like to thank Andrew Brenner, Anna-Sofia Maurin, Alexander Skiles, Naomi Thompson and Tobias Wilsch for their invaluable comments on an earlier version of this paper.

Funding Open access funding provided by Lund University. Funding was provided by Riksbankens Jubileumsfond (Grand No. P16-0541:1).

Open Access This article is licensed under a Creative Commons Attribution 4.0 International License, which permits use, sharing, adaptation, distribution and reproduction in any medium or format, as long as you give appropriate credit to the original author(s) and the source, provide a link to the Creative Commons licence, and indicate if changes were made. The images or other third party material in this article are included in the article's Creative Commons licence, unless indicated otherwise in a credit line to the material. If material is not included in the article's Creative Commons licence and your intended use is not permitted by statutory regulation or exceeds the permitted use, you will need to obtain permission directly from the copyright holder. To view a copy of this licence, visit http://creativecommons.org/licen ses/by/4.0/.

\footnotetext{
27 There might be exceptions as, for example, when there are propositions seems sufficient to ground its own truth and existence (cf. Rodriguez-Pereyra 2015). For the sake of the argument, however, we may ignore such cases.

${ }^{28}$ Notice that there is no equivocation involved when we move from the second term in (4) to the first term in (5). It is the truth of Socrates exists that acts as both ground and groundee in each instance.

29 Similarly, in relation to (1)-(3). To provide a sufficient ground for [there are alethic facts is true], we need, in addition to Socrates, the proposition that Socrates exists.
} 


\section{References}

Armstrong, D. M. (1997). A world of states of affairs. Cambridge University Press.

Armstrong, D. M. (2004). Truth and truthmakers. Cambridge University Press.

Armstrong, D. M. (2007). Truthmakers for negative truths and for truths of mere possibility. In J. Monnoyer (Ed.), Metaphysics and truthmakers (pp. 99-104). Frankfurt: Ontos Verlag.

Asay, J. (2017). Run aground: kit fine's critique of truthmaker theory. The Philosophical Quarterly, 67(268), 443-463.

Audi, P. (2012). A clarification and defense of the notion of grounding. in F. Correia, B. Schnieder, pp. $101-121$.

Cameron, R. (2008). Truthmakers, realism and ontology. In R. LePoidevin (Ed.), Being: Contemporary developments in metaphysics (Vol. 83, pp. 107-128). Royal Institute of Philosophy Supplement.

Cameron, R. (2008b). How to be a truthmaker maximalist. Noûs, 42(3), 410-421.

Candlish, S. (2015). The identity theory of truth. in Stanford encyclopedia of philosophy, https://plato. stanford.edu/entries/truth-identity/.

Correia, F. (2010). Grounding and truth-functions. Logique Et Analyse, 53(211), 251-279.

Correia, F. (2011). From grounding to truth-making: Some thoughts. In A. Reboul (Ed.), Mind, values, and metaphysics: Philosophical essays in honor of Kevin Mulligan (Vol. I, pp. 85-98). Springer.

Correia, F., \& Schnieder, B. (Eds.). (2012). Metaphysical grounding: Understanding the structure of reality. Cambridge University Press.

Dasgupta, S. (2014). The possibility of physicalism. Journal of Philosophy, 111(9), 557-592.

Fine, K. (2012). Guide to ground. Correia \& Schnieder, 2012, 37-80.

Glazier, M. (2016). Laws and the completeness of the fundamental. In M. Jago (Ed.), Reality making (pp. 11-37). Oxford University Press.

Griffith, A. M. (2014). Truthmaking and grounding. Inquiry, 56(2), 196-215.

Keller, P. (2009). Review of truth and truthmakers. Mind, 118(472), 1101-1105.

Kment, B. (2014). Modality and explanatory reasoning. Oxford University Press.

Lewis, D. (1986). On the plurality of worlds. Blackwell.

Litland, J. E. (2013). On some counterexamples to the transitivity of grounding. Essays in Philosophy, 14(1), 19-32.

Mellor, D. H. (1995). The facts of causation. Routledge.

Pawl, T. (2010). The possibility principle and the truthmakers for modal truths. Australasian Journal of Philosophy, 88(3), 417-428.

Plantinga, A. (1974). The nature of necessity. Clarendon Press.

Raven, M. (2013). Is ground a strict partial order? American Philosophical Quarterly, 50(2), 191-199.

Raven, M. (2016). Fundamentality without foundations. Philosophy and Phenomenological Research, 93(3), 607-626.

Read, S. (2000). Truth-makers and the disjunction thesis. Mind, 109, 67-79.

Restall, G. (1996). Truth-makers, entailment and necessity. Australasian Journal of Philosophy, 74, 331-340.

Rodriguez-Pereyra, G. (2005). Why truthmakers? In H. Beebee \& J. Dodd (Eds.), Truthmakers: The contemporary debate (pp. 17-31). Oxford University Press.

Rodriguez-Pereyra, G. (2006). Truthmaking, entailment, and the conjunction thesis. Mind, 115(460), 957-982.

Rodriguez-Pereyra, G. (2015). Grounding is not a strict order. Journal of the American Philosophical Association, 1, 517-34.

Rosen, G. (2010). Metaphysical dependence: Grounding and redusction. In R. Hale \& A. Hoffman (Eds.), Modality: Metaphysics, logic, and epistemology (pp. 109-136). Oxford University Press.

Schaffer, J. (2008). Truth and fundamentality: On Merrick's truth and ontology. Philosophical Books, 49, $302-316$.

Schaffer, J. (2009). "On what grounds what" in Chalmers. In D. Chalmers, D. Manley, \& R. Wasserman (Eds.), Metametaphysics (pp. 347-383). Oxford University Press.

Schaffer, J. (2012). Grounding, transitivity, and contrastivity. In F. Correia \& B. Schnieder (Eds.), Metaphysical grounding: Understanding the structure of reality (pp. 122-138). Cambridge: Cambridge University Press.

Schaffer, J. (2017). Laws for metaphysical explanation. Philosophical Issues, 27, 302-321.

Tahko, T. (2013). Truth-grounding and transitivity. Thought, 2(4), 332-340. 
Trogdon, K. (2018). Grounding-mechanical explanation. Philosophical Studies, 175, 1289-1309.

Trogdon, K. (2020). Truthmaking. In M. Raven (Ed.), Routledge handbook of metaphysical grounding (pp. 396-407). Routledge.

Wilsch, T. (2015). The nomological account of ground. Philosophical Studies, 172, 3293-3312.

Publisher's Note Springer Nature remains neutral with regard to jurisdictional claims in published maps and institutional affiliations. 